\title{
POIS APRENDENDO A LER, HAVEMOS DE ENXERGAR:* ALFABETIZAÇÃO DE ADULTOS NAS ESCOLAS RADIOFÔNICAS DE PERNAMBUCO (1961-1966) ${ }^{\star *}$
}

\author{
Kelly Ludkiewicz Alves ${ }^{* *}$
}

\section{RESUMO}

A pesquisa investiga a participação das monitoras e monitores na alfabetização dos adultos camponeses e na educação de base, assim como suas práticas nas escolas radiofônicas em Pernambuco, entre 1961 e 1966. Apontamos também os limites impostos ao cotidiano das escolas, pela realidade econômica e social das populações rurais. Investigamos uma mostra de 649 cartas, além de relatórios e materiais para treinamento, produzidos pelo Movimento de Educação de Base (MEB).

Palavras-chave: práticas, alfabetização de adultos, escola radiofônica, cultura escrita.

\footnotetext{
* Trecho de poema da monitora Generosa, 1964.

${ }^{* *}$ Este texto é parte dos resultados da tese defendida no Programa de Estudos Pós Graduados em Educação: História, Política, Sociedade da Pontifícia Universidade Católica de São Paulo, que contou com financiamento do Conselho Nacional de Desenvolvimento Científico e Tecnológico (CNPQ) e do Programa de Bolsa Sanduíche (PDSE/CAPES).

${ }^{* * *}$ Universidade Federal da Bahia (UFBA), Salvador/BA, Brasil.
} 


\section{PUES APRENDIENDO A LEER, HEMOS DE VER: ALFABETIZACIÓN DE ADULTOS EN LAS ESCUELAS RADIOFÓNICAS DE PERNAMBUCO (1961-1966)}

\section{RESUMEN}

La investigación aborda la participación de monitores en la alfabetización de los adultos campesinos y en la educación de base, así como sus prácticas en las escuelas radiofónicas en Pernambuco (1961-1966). También señalamos los límites impuestos a la vida diaria de las escuelas, por la realidad económica y social de las poblaciones rurales. Trabajamos con una muestra de 649 cartas, así como informes y materiales de capacitación producidos por el Movimento de Educação de Base (MEB).

Palabras clave: prácticas, alfabetización de adultos, escuela radiofónica, cultura escrita.

\section{THEN LEARNING TO READ WE'LL BE ABLE TO SEE: ADULT LITERACY IN THE RADIO SCHOOLS OF PERNAMBUCO (1961-1966)}

\section{ABSTRACT}

The research focuses on the literacy teachers' participation in the education of the adult rural population, such as in its practices in the Pernambuco radio school (1961-1966). We point out as well the limits imposed daily on the schools by the economic and social reality of the rural populations. We investigate an exhibition of 649 letters, along with reports and material for training produced by the Movimento de Educação de Base (MEB).

Keywords: practices, adult literacy, radio school, written culture.

\section{POUR APPRENDRE À LIRE, IL FAUT VOIR: ALPHABÉTISATION DES ADULTES DANS LES ÉCOLES DE RADIO À PERNAMBUCO (1961-1966)}

\section{RÉSUMÉ}

La recherche consiste à analyser la participation des moniteurs à l'alphabétisation des adultes paysans et à l'éducation de base, et d'autre part à étudier leurs pratiques pédagogiques dans les écoles radiophoniques dans l'Etat de Pernambuco (1961-1966). Nous mettons également en exergue les limites imposées par la réalité économique et sociale des populations rurales dans leur quotidien scolaire. Pour y parvenir, nous comptons sur un corpus de 649 lettres, en plus des rapports et matériaux pour leur formation, produits par le Movimento de Educação de Base (MEB).

Mots-clés: pratiques, alphabétisation des adultes, école de radio, culture écrite. 


\section{INTRODUÇÃO}

Sítio Araruna, $1^{\circ}$ de maio de 1964.

Prezadas supervisoras Dinalva, dona Zélia, etc.

Hoje $1^{\circ}$ de maio dia comemorado as classes operárias, (o trabalhador), que Deus ilumine os nossos trabalhos de monitores, concedendo-nos um bom êxito. Depois de muito pensar, rezolvi fazer-lhes esta a fim de esclarecer-lhes o que desejo. Apezar de que ainda não me foi possível êste ano, atender aos nossos alunos as aulas do mês de abril, pois prezadas supervisoras é o seguinte: $1^{\circ}$ Não consegui arranjar querozene, nem reunindo os alunos, pois os mesmos agora não têem dinheiro. $2^{\circ}$ O mês de abril foi quase todo de chuvas pela a noitinha, mutivo êste, justo para a não vinda dos alunos, além das chuvas, passagem por forte riacho. Eu tinha dó deles e tenho lamento muito terem perdido um mês de aula, mas farei o possível para retransmitir as mesmas para eles, como os tenho falado. Parece incrível, que foi tudo dessa maneira. Apareceu uma gripe tão forte deixando as pessoas semanas de cama, eu fui uma das vítimas e que mais fiquei abatida, não aguentando dar aulas. Assim - em lugar de remeter a folha de frequência do referido mês, remeto-lhe esta, certa de que não irá agradar-lhes. Mas se Deus quizer logo irei reuni-los novamente ver se consigo o querozene e o dinheiro do material que trouxe pelo treinamento, pois tem que sêr tentativa sobre tentativa. Agora estamos melhores de saúde e as chuvas estão menas, vamos começar se Deus quizer... Gostaria que me arranjassem mais uma antena, pois a que mandaram emprestei para uma amiga pelas férias e ela ainda não devolveu-me e o rádio só fonciona bem com uma bôa antena. Como também tenho idéia de dividir as turmas para duas classes, como seja: na salinha que é demais pequena e no alpendre. Arranjo uma auxiliar e peço-lhes para arranjarem-me mais um quadro-negro e um aladim, visto que, um só não clareia no alpendre. Pois pelo menos nesta parte precizamos de um certo conforto, não é verdade? Tenho acompanhado as aulas desde o dia $1^{\circ}$ esto é, ( 30 de março). Certa que serei atendida e aguardando uma bôa resposta, antecipo os meus sinceros agradecimentos. Recebam um abraço amigo da monitora.

Adélia Aires da Cruz e não Cunha

P.S. Sempre fui cumpridora dos meus deveres quero continuar se Deus quizer.

Adélia escreveu, no dia do trabalhador de 1964, este relato que nos conta um pouco do que era a vida da população rural nos idos da década de 1960. A carta é o testemunho de uma das mais de 7000 monitoras e monitores que 
trabalharam nas escolas radiofônicas, criadas pelo Movimento de Educação de Base (MEB), e que se utilizaram das cartas e do rádio como meios de comunicação ${ }^{2}$. Ao lermos seu relato podemos reconstruir elementos da paisagem das comunidades rurais de Pernambuco, com suas ruas de terra e casas com alpendre, onde viviam mulheres e homens que percorriam longas distâncias enfrentando as intempéries da natureza para chegar à escola. Adélia nos fala das pessoas, dos amigos, dos problemas de saúde, da falta de dinheiro, das condições materiais de sua comunidade; ela também nos chama a atenção, para a vida cotidiana e como esta se impõe, fazendo com que os acontecimentos tenham dinâmicas próprias que, na maioria das vezes, não correspondem diretamente à expectativa ou ao discurso do MEB3.

Na carta, a monitora dá voz aos anseios que nutre em relação à escola radiofônica e exprime suas estratégias, ou jeitos de fazer, relacionados ao trabalho de educação dos adultos que realizava em sua comunidade. Ela também relata às supervisoras do MEB as vicissitudes que se impunham para que a escola radiofônica começasse a funcionar e apresenta as alternativas para que os alunos pudessem, finalmente, ter a oportunidade de frequentar a escola e ouvir as aulas pelo rádio. Escritos como este revelam a experiência cotidiana das escolas radiofônicas no âmbito do MEB em Pernambuco, através da visibilidade que dão às expectativas e as demandas da população camponesa em relação à alfabetização, bem como aos limites para sua realização.

Alguns historiadores da educação já têm apontado para o diálogo

\footnotetext{
${ }^{2} \mathrm{Na}$ transcrição das cartas optamos por manter a grafia original e as características anteriores à Reforma Ortográfica de 1971.

3 A escola radiofônica de Adélia foi uma das muitas escolas abertas pelo MEB, com o objetivo promover a alfabetização de adultos nos meios rurais por meio de uma programação radiofônica educativa veiculada diariamente via emissoras de rádio. Foi criado oficialmente em 1961, por meio de um convênio feito entre a Igreja Católica, representada pela Conferência Nacional dos Bispos do Brasil (CNBB), e o governo federal, que se aliava à Igreja para fortalecer sua política para educação dos adultos, criticada no final dos anos 1950 (PAIVA, 1983; FREITAS; BICCAS, 2009). O MEB atuou inicialmente na Região Nordeste e no Norte de Minas Gerais; em Pernambuco, iniciou suas atividades em 1961 e começou seu processo de esvaziamento em 1966, que levou ao encerramento de suas atividades no Estado, por questões relacionadas à falta de verbas e à instauração do regime autoritário que sucedeu o Golpe Civil-Militar de 1964 (TEIXEIRA, 2008).
} 
frutífero entre o campo e a história da cultura escrita (CASTILLO GÓMEZ, 2003, 2002; GALVÃO, 2007, 2011; CHARTIER, 2019). A partir dele, compreendemos a relação que esses educadores estabeleceram com a leitura e a escrita, tendo em vista uma variedade de práticas, que estão presentes em uma determinada cultura, por meio das quais se atribuem usos e significados diversos à língua escrita e a oralidade (CASTILLO GÓMEZ, 2005; CASTILLO GÓMEZ; SIERRA BLAS, 2014). Ademais, partimos da compreensão de que as práticas culturais não procedem tão somente de uma ordem social constituída, mas são elementos importantes em sua constituição (WILLIAMS, 1992). Assim, a trama que tecemos neste estudo procurou conhecer a experiência e o cotidiano das escolas radiofônicas do MEB, a partir de um sistema de significações, por meio do qual uma cultura é comunicada, reproduzida, vivenciada e estudada (VEYNE, 2014; WILLIAMS, 1992).

Assumindo tal perspectiva temos como objetivo identificar, a partir dos relatos escritos nas cartas 4 , as práticas das monitoras e monitores nas escolas radiofônicas, abertas pelo MEB em comunidades rurais de Pernambuco, nos anos de 1961 a 1966. Destacando de sua experiência nas escolas radiofônicas, os aspectos relacionados à sua formação, as expectativas com relação ao trabalho de alfabetização e mobilização dos adultos, assim como as dificuldades cotidianamente enfrentadas, que em muitos momentos impôs limites à realização de sua tarefa.

Na primeira parte da análise, utilizamos as fontes produzidas pelo MEB, como roteiros de aulas radiofônicas, relatórios e planos de atividades, a fim de compreender o sentido que o MEB atribuía à ação das monitoras e monitores

\footnotetext{
4 Diante da quantidade de cartas analisadas na pesquisa de doutorado, da qual deriva este texto, para organizar e analisar as fontes foi desenvolvido um banco de dados que totaliza 649 registros das cartas selecionadas no acervo. Estas foram classificas por meio de palavras-chaves, que permitiram identificar na amostra, os temas mais recorrentes nas correspondências, além de classificá-las a partir da natureza dos assuntos tratados. Foram definidas 62 palavras-chave utilizadas para classificação das mesmas, que foram divididas em quatro blocos temáticos tendo em vista os objetivos da pesquisa: 1) ensino, aprendizagem e cotidiano das escolas radiofônicas; 2) organização e manutenção das escolas radiofônicas; 3) conteúdos políticos e pedagógicos do MEB; 4) assuntos da comunidade, condições de vida e de trabalho.
} 
naquele contexto. Nosso intuito foi identificar nos pressupostos de sua ação pedagógica, que contemplavam duas dimensões - a alfabetização por meio da educação de base e a organização da comunidade - o perfil das monitoras e dos monitores e em que consistiam as funções a serem desempenhadas por eles nas escolas radiofônicas e junto à comunidade. Na segunda parte, apresentamos, por meio das cartas, as práticas que se estabeleceram nesses espaços, as expectativas e as dificuldades com relação à realização do trabalho de alfabetização.

Nosso objetivo de conhecer a experiência e o cotidiano das monitoras e monitores nas escolas radiofônicas se deve a compreensão de que estas se constituíram em espaços de formação e inserção das populações rurais no universo da cultura escrita, tendo em vista a alfabetização, o intercambio epistolar, a produção de poemas e de cordéis, assim como a circulação destes, por meio da programação radiofônica (ALVES, 2016).

Assim como assinala Claudia Moraes de Souza, em sua pesquisa desenvolvida no campo da história social, entendemos as escolas radiofônicas como um espaço de relações, onde os camponeses puderam pôr em prática sua noção própria de modernização, configurando-as como lugares de produção de relações e representações políticas singulares relativas à escola, ao sindicato, ao trabalho, ao direito a terra e ao uso do rádio como veículo de comunicação, informação e lazer (SOUZA, 2006). A historiadora também aponta para o fato de que a circulação de tais representações políticas singulares se deu a partir da inserção do rádio nas escolas e da comunicação pelas cartas, como elementos integrantes dessa modernidade, incorporados pelos camponeses como "mecanismos ágeis de comunicação social a serviço da comunidade" (SOUZA, 2006, p. 27).

Outras pesquisas que tomaram o MEB como objeto de estudo, algumas delas produzidas por militantes do movimento, apresentam de uma forma geral, as relações entre a proposta pedagógica, o modelo de educação e a conjuntura política de sua criação. Também possibilitam conhecer os aspectos relativos à estrutura do MEB em sua relação com o Estado, investigados no âmbito de uma 
história das políticas educacionais institucionais, dos movimentos sociais e das ideias e modelos pedagógicos (FÁVERO, 1996; KADT, 2007; COSTA; BRANDÃO, 1985; WANDERLEY, 1984; PAIVA; 1983).

A criação do MEB é fruto de uma aglutinação de interesses que respondem, em parte, à política do Estado brasileiro no campo educativo, que desde finais da década de 1940, promovia ações voltadas para a alfabetização dos adultos, tendo em vista, a tão proclamada necessidade de promover a formação do povo brasileiro, por meio de seu acesso às letras, visando sua integração à nação (BEISIEGEL, 2004; FREITAS; BICCAS, 2009). Destaca-se, nesse sentido, a Campanha de Educação de Adultos, que foi o primeiro projeto em âmbito nacional voltado para a educação dos adultos, e tinha como objetivo promover uma "educação de base" a todos os brasileiros que viviam nas zonas urbana ou rural, que não soubessem ler e escrever. A Campanha foi amplamente divulgada nos municípios por meio da comunicação impressa e radiofônica, o que contribuiu para sua visibilidade, conclamando o povo a participar, fosse como aluno, professor ou colaborador (FREITAS; BICCAS, 2009). A projeção nacional da experiência nos meios de comunicação foi um dos fatores que contribuíram para propagar socialmente a valorização do acesso à alfabetização como necessária ao desenvolvimento brasileiro.

A criação do MEB também correspondeu às distintas motivações oriundas da Igreja Católica. Institucionalmente, a Igreja desejava conter o avanço dos movimentos populares de luta pela terra, identificados com o comunismo, e promover uma ação evangelizadora por meio do trabalho de base que a aproximasse das populações camponesas e contribuísse para sua expansão no meio rural. Paralelo às motivações institucionais que contribuíram para a criação do MEB, havia a ação de grupos de católicos leigos que atuavam em outros espaços políticos e que viam no movimento a possibilidade de atuar como militantes engajados na luta pela educação e organização dos trabalhadores rurais (KADT, 2007; PAIVA, 1983).

Desde o final da década de 1950, esse grupo de educadores católicos 
leigos vinha tecendo severas críticas ao modelo de educação dos adultos, comumente praticado pelo Estado. Em 1958, Paulo Freire, que integrava o grupo de Pernambuco, produziu um relatório no qual enfatizava que o problema do povo nordestino não era o analfabetismo e sim a miséria. A partir de então, ainda que o tema da educação dos adultos seguisse atrelado ao projeto desenvolvimentista do Estado brasileiro, sua dimensão de ação ampliou-se para a defesa de ações direcionadas à formação da consciência do povo (FREITAS; BICCAS, 2009). O MEB foi um ator chave para essa mudança de perspectiva, sendo seu modelo de educação dos adultos, denominado de Educação de Base, diretamente influenciado pela pedagogia freireana no que se refere à descentralização, à regionalização do ensino e a necessidade de adaptar a educação dos adultos à cultura local, pensando a comunidade e a escola de maneira integrada (FREITAS; BICCAS, 2009).

Em meados de 1964, o MEB produziu um documento onde sintetizava seus objetivos para o ano seguinte em relação às escolas radiofônicas e dava subsídios para a elaboração das atividades. Segundo o texto, as ações do MEB tinham na promoção da conscientização o princípio básico da ação educativa, vista como:

[intrínseca] à própria educação, pois ela significa ajudar alguém a tomar consciência do que ele é (consciência de si), do que são os outros (comunicação dos dois sujeitos) e do que é o mundo (coisa intencionada), que são os três polos de tôda educação integral (MEB/Escolas Radiofônicas, [1964], p. 4).

Assim, as atividades nas escolas radiofônicas deveriam orientar-se, respectivamente, para a "conscientização, mudança de atitudes e instrumentação das comunidades" (MEB/Escolas Radiofônicas, [1964], p. 3). Essa concepção da ação educativa compreendia a ação das monitoras e dos monitores como potencialmente capaz de intervir na transformação da realidade, de modo que os camponeses deveriam ser despertados e estimulados a partir do conhecimento e 
da sensibilização para os problemas que afetavam a comunidade.

Para o movimento, a ação das escolas radiofônicas não deveria se esgotar nos objetivos da alfabetização, pois se diferenciando de uma escola convencional, deveria "ser entendida dentro do conjunto maior das atividades e da vida de tôda a comunidade camponesa" (MEB/Escolas Radiofônicas, [1964], p. 1), propondo também que sua ação integrasse a alfabetização à organização da comunidade a partir de outros espaços, tais como sindicatos, clubes de mães, clubes agrícolas, cooperativas, etc. Assim, seu modelo de educação dos adultos não estava restrito a noção escolar, o que contribuiu para que as escolas radiofônicas se constituíssem em espaços de organização, formação, produção e circulação da cultura camponesa.

\section{MONITORAS E MONITORES: SÃO ELAS E ELES QUE ANIMAM OS ALUNOS}

Para que a proposta de ação pedagógica do MEB pudesse ser exitosa, era preciso, portanto, que as monitoras e os monitores conhecessem os problemas das comunidades e da sua realidade, além de promoverem outras formas de organização política, que estavam além da transmissão do conteúdo das aulas (MEB/Escolas Radiofônicas. [1964]). Assim, eles eram os responsáveis por realizar o trabalho de base junto à comunidade, com o objetivo de mobilizar ou animar as pessoas que se mostrassem interessadas em frequentar a escola, instruir-se e organizar-se.

A escolha das monitoras e monitores era parte do processo de radicação das escolas radiofônicas, que começava com a identificação das áreas mais necessitadas, por meio de um estudo de área, seguida da escolha de uma pessoa da comunidade para atuar na escola. Uma vez selecionados, as monitoras e os monitores eram os responsáveis por fazer a matrícula dos alunos que desejassem frequentar as aulas. Desse modo, sua função era fundamental por estabelecer os 
primeiros contatos diretos com os alunos e a comunidade, do que dependia, em grande medida, o sucesso da escola radiofônica5.

Após a abertura da escola radiofônica, as monitoras e os monitores deveriam atentar-se para as tarefas cotidianas de organização, horário de transmissão dos programas e registro de presença na folha de frequência, que deveria ser enviada mensalmente às equipes locais juntamente com um relatório mensal das atividades (MEB/Documentos legais. Apostila 1, s.d). Assim, suas atribuições começavam pela instalação da escola, geralmente na sua própria residência, seguido da gestão, dos cuidados com higiene e arrumação e do contato com as supervisoras.

Quanto ao cotidiano das aulas, era esperado que as monitoras e os monitores fossem assíduos em orientar os alunos de acordo com as instruções dadas pelo professor-locutor. Deveriam estar atentos ao aprendizado dos alunos, estimulá-los a atender a cada um, ajudando-os em suas necessidades, além de dispensar atenção especial àqueles que apresentassem mais dificuldades de aprendizado e fomentar a colaboração dos alunos mais adiantados. Por fim, era esperado que promovessem debates com os alunos, incentivando-os a relacionar os temas abordados com a situação da comunidade (MEB. O monitor, s/d.).

Em um Programa do Monitor transmitido aos finais de semana como parte da programação especial para formação das monitoras e monitores, a professora locutora diz:

\footnotetext{
5 O MEB teve forte penetração no meio rural, precisamente nas regiões Norte, Nordeste e CentroOeste e no Estado de Minas Gerais. Estava presente em 14 estados brasileiros no início de 1964. Em 1963, atingiu em nível nacional o número máximo de escolas radiofônicas: 7353. Entre 1961 e 1965 o número de alunos concluintes foi de aproximadamente 380 mil. Em março de 1964, trabalhavam no movimento 542 pessoas, entre técnicos, administradores e supervisores. Ao longo de toda sua existência, o movimento capacitou 13770 pessoas entre professores, supervisores, animadores populares e monitores dos quais, em 1963, 7500 eram voluntários. Ao longo dos cinco primeiros anos de atuação em Pernambuco, o total de alunos concluintes foi de 65.574 (WANDERLEY, 1984). A população total do Estado em 1965 era de aproximadamente 4.500.00o habitantes, o que significa que durante sua atuação o sistema atendeu cerca de 1,5\% da população do Estado.
} 
O monitor é a chave do êxito da Escola Radiofônica. É ele que anima os alunos e todos os que moram nas redondezas para as tarefas de aprender, de se reunir para conversar sobre seus problemas, para fazer uma campanha. O monitor, neste trabalho, melhora cada dia pois há assim uma verdadeira troca, êle leva aos alunos o que êle sabe e aprende muita coisa do aluno que tem muitas riquezas a informar (MEB/Sistema Radioeducativo de Olinda e Recife. Programa do Monitor, 1963, p. 1).

Essa expectativa em relação ao engajamento das monitoras e dos monitores nas tarefas da escola radiofônica ultrapassava, de fato, suas funções escolares diárias e incumbia-lhes de uma atuação política que se concretizava na sua tarefa de animador popular: "É ele que anima os alunos e todos os que moram nas redondezas" (MEB. O monitor, s/d, p. 02). Desse modo, as características pessoais que deveriam orientar a escolha eram de duas naturezas: ter capacitação técnica mínima para conduzir a escola, isto é, ser alfabetizado; social e intersubjetivamente, consideravam-se as suas relações, sua capacidade de inserção na comunidade e seus traços de personalidade, tais como liderança, competência e responsabilidade.

O mínimo indispensável é que o monitor seja alfabetizado (saiba ler,
escrever, contar) conscientemente interessado, para trabalhar
voluntariamente [...] seja uma pessoa da comunidade [...] uma pessoa
representativa, poderá exercer uma liderança autêntica e democrática
[...] a competência é sua qualidade essencial; é indispensável que o
monitor saiba o que fazer, onde, quando e como [...] toda a atividade do
monitor é um serviço; sua atuação não pode centrar-se nêle mesmo [...]
mas (n)a de sua comunidade. [...] um sentido autêntico de
responsabilidade (MEB. O monitor [grifos originais], s/d, p. 3).

Evidencia-se a intenção de engajar pessoas com determinadas características, "a fim de que o MEB conte com pessoas ajustadas, cuja ação seja, de fato, eficiente" (MEB. O monitor, s/d, p. o3). A eficiência, entendida como "o melhor rendimento possível em uma atividade" consistia também na capacidade de se conformar com a realidade enfrentada e suas necessidades (MEB. O monitor, s/d, p. 03). 
Quando iniciavam o trabalho nas escolas, algumas monitoras e monitores participavam de treinamentos promovidos pelas supervisoras do MEB. Essas ocasiões tinham como objetivo prepará-los para o trabalho nas escolas radiofônicas, tendo em vista "duas grandes linhas: a conscientização e a capacitação dos treinandos para suas funções no MEB”. Essas duas direções consistiam em: conscientizá-los de seu papel na escola e na comunidade, por meio de atividades e dinâmicas que partissem da sua realidade que lhes possibilitassem "agir para modificar as estruturas injustas e inumanas" (MEB. O monitor, $\mathrm{s} / \mathrm{d}, \mathrm{p}$. 05). O segundo aspecto do treinamento consistia em apresentalhes os objetivos das aulas, os recursos de que dispunham e as técnicas de avaliação.

Num relatório elaborado com o objetivo de apresentar dados de entrevistas feitas durante o treinamento, realizado em 1961 na região da Zona da Mata, apresentam-se elementos identificadores do perfil ideal que se buscava, neste momento inicial, em que se definem os primeiros grupos que iriam atuar nas escolas radiofônicas.

Para traçar o perfil condizente com suas funções se observa aspectos que, segundo o relatório do MEB, seriam reveladores do temperamento dos monitores: "Disposta e alegre"; "Alegre, simples"; "Muito comunicativa, alegre"; "Inteligente, líder, demonstra iniciativa”; “Líder. É tudo no engenho”; “Tem uma vontade louca de aprender. É um sonho de toda vida”; "Goza de certa liderança no Engenho. É responsável"; "Muito embaraçada. Sem iniciativa"; "Muito tímido"; "Tímida. Criança (pouco amadurecida)". O texto também faz "observações para possíveis programas de desenvolvimento de comunidade" enfatizando os campos de atuação, que correspondiam aos interesses do MEB, tais como: "Promove festas para alunos e pais", "Pertence a JAC" (Juventude Agrária Católica), "Goza de liderança no engenho" e "Colabora com a Paróquia” ou "Tem uma grande vontade de ajudar com a comunidade" (MEB/Centro Radiofônico de Educação Rural. Relatório de Treinamento de Monitores, 1961, p. 04). 
Participaram do treinamento 35 monitoras e sete monitores, a maior parte, jovens, que tinham entre 15 e 25 anos de idade. Na faixa etária entre 26 e 35 anos, havia oito monitores e seis que tinham entre 36 e 47 anos de idade. Quanto ao grau de instrução:

[...] a maioria não ultrapassa o nível do curso primário, [mas] levando em conta que o curso primário tenha sido realmente aproveitado, e o tipo de trabalho a realizar, julgamos o nível de instrução razoável. Tanto isto é verdade, que êstes elementos - na sua maioria já se dedicam ao magistério" (MEB/Centro Radiofônico de Educação Rural. Relatório de Treinamento de Monitores, 1961, p. 2).

Do grupo, 35 eram professoras da rede municipal, duas da rede estadual, uma atuava como auxiliar de escola, duas bordadeiras, uma costureira e quatro domésticas. Entre os homens, três eram agricultores, um pedreiro, um operário e dois estudantes. Note-se que a maioria do grupo era formado por mulheres, quase todas professoras, o que também foi característico em outros Estados em que o MEB atuou (FERRARI, 1968).

Para o movimento, o engajamento de monitoras que já se dedicavam à docência era positivo sob dois aspectos: experiência com alfabetização e o seu reconhecimento na comunidade. Desse modo, o perfil do grupo atendia às expectativas de seleção no que se refere à formação, considerada razoável, e às potencialidades de ação. A significativa quantidade de professoras poderia contribuir no trabalho de animação popular e de radicação de escolas, já que eram conhecidas em suas comunidades por seu trabalho docente, e o fato de contar com três agricultores "representa um valor, positivo para o nosso trabalho, como transmissor de experiência" (MEB/Centro Radiofônico de Educação Rural. Relatório de Treinamento de Monitores, 1961, p. 2).

Alguns fatores teriam sido determinantes para que as mulheres fossem maioria e, ao mesmo tempo, a quantidade de agricultores fosse pequena nas escolas radiofônicas. Primeiro, as próprias condições de trabalho em algumas 
regiões, uma vez que "as mulheres não ocupavam postos de trabalho formais nas relações de produção", e por isso, as mulheres da família não estavam diretamente ligadas ao trabalho de corte da cana, por exemplo (SOUZA, 2006, p.120). Como a jornada de trabalho na lavoura era, geralmente, de um dia inteiro, e as atividades nas escolas radiofônicas demandavam uma média de três horas diárias de trabalho voluntário, tornava-se difícil a um lavrador dedicar-se às tarefas escolares:

\footnotetext{
Vou apreciando bastante as aulas apesar de ter começado atrasado e que a senhora está advinhando a nossa luta da roça a qual não é brincadeira a gente sair as 6 da manhã e trabalhar até as 17 e as 18 esta no pé do radio: só quem precisa [...] é que pode fazer isto? E bem serto diser quem caça o sapato e que sabe onde aperta (José, 14/05/64).
}

Outra explicação "advém da representação da figura feminina no ambiente escolar" e do fato de que "a figura da professora predominava na cultura do homem rural e a associação entre a monitora e a docência foi um fato significativo a se considerar" (SOUZA, 2006, p. 120). Tendo em vista o conjunto das cartas, o grupo do treinamento e os dados apresentados por Alceu Ferraro, uma parcela significativa das monitoras lecionava também em outras escolas, e a predominância de mulheres também se devia à sua experiência docente e a possibilidade de se engajar num trabalho de caráter voluntário. Além do fato de que seria mais fácil para as monitoras que já atuavam como professoras reunir alunos suficientes para abrir uma escola radiofônica por meio de "visitas, reuniões e propaganda" (FERRARI, 1968).

Temos apontado que as tarefas nas escolas radiofônicas eram numerosas e diversas, demandando uma parte significativa de tempo diário, a ser dividido com as tarefas domésticas e outras atividades profissionais: "meus alunos estão frequentando as aulas muito pouca porque estão tudo trabalhando em desmancha e até eu com minha família ainda estamos nesta luta" (Raimunda, 23/06/64). Ademais, boa parte das monitoras era jovem e solteira, não sendo 
raro que se desvinculassem das escolas radiofônicas por motivo de casamento: "Venho lhe avizar que eu não vou mais ensinar a ER não. Proque! Eu vou mim cazar agora em dezembro [...]" (Maria do Carmo, o6/o8/64). É certo que houve outros fatores, relativos à condição da mulher no meio rural, decisivos para o abandono desses espaços; certamente os casamentos disputavam o tempo com o trabalho na escola radiofônica, que exigia uma dedicação diária significativa.

Um aspecto observado a respeito dos treinamentos realizados em Pernambuco é o fato de que essas ocasiões de encontro estavam mais voltadas para a formação política das monitoras e dos monitores, destacando seu papel como agentes articuladores da organização dos camponeses (ALVES, 2016). Nessas ocasiões era dada menor atenção aos aspectos relacionados à abertura de escolas e a formação sobre o conteúdo das aulas radiofônicas, e tampouco ao que se refere às práticas de alfabetização dos adultos, ou alguma discussão sobre as dificuldades geralmente enfrentadas no cotidiano das escolas.

As monitoras e os monitores que participavam dos treinamentos, por sua vez, ficavam satisfeitos e sentiam-se mais instruídos em relação a sua própria realidade, de modo que viam os conteúdos abordados nessas ocasiões como significativos do ponto de vista da formação para a abordagem de temas relacionados à realidade social da população rural:

Eu acho que o treinamento é uma grande ajuda para nós, porque se não houvesse este treinamento nos não tinha tanto conhecimento da vida dos camponezes como estamos vendo [...] devemos ajudar a nossa comunidade trabalhando um a bem do outro para vivermos uma vida que não custe tão caro e voltamos mesmo bem esclarecido tanto em escrever como da nossa vida (Eliza, s. d).

Eu sendo monitora nesta localidade, porem incompetente, por não ter feito o curso de monitora. Mesmo assim vou agindo pelo melhoramento de nosso país. Desde que essa escola ficou a meu cargo que venho combatendo os lamentos dos alunos: o radio transmite a aula de matemática eu dou a de linguagem sempre trocando entende, e no fim das aulas eu costumo tomar as lições de livros e taboadas, apenas as lições eu só tomo quando é dada pelo rádio. Estará de acordo? (Maria José, 02/10/63). 
Entretanto, como pode se observar no relato da monitora Maria José, nem todos tinham a possibilidade de participar dos treinamentos e, neste caso, muitos se utilizavam das cartas como meio para tirarem suas dúvidas sobre o modo de encaminhar as aulas. Geralmente solicitavam que as mesmas fossem respondidas durante as aulas radiofônicas, que ao longo da existência do MEB em Pernambuco, foram um importante veículo de formação das monitoras e monitores para a prática nas escolas radiofônicas, diante da impossibilidade de participarem dos treinamentos e das dificuldades relacionadas aos conteúdos das aulas e a forma como abordá-los com os alunos.

Como podemos ver nos documentos produzidos pelo MEB, buscava-se um perfil de militante, cujos critérios para escolha estavam muito mais alinhados à sua predisposição ou possibilidade de envolvimento com o MEB junto à comunidade. A organização e gestão da escola e a educação dos alunos, ainda que estivessem presentes no rol de atribuições das monitoras e monitores, apareciam como tarefas inerentes à pessoa com o perfil de liderança esperado pelo movimento. Provavelmente, devido às experiências anteriores, o MEB já reconhecia a importância das monitoras e monitores para o êxito do projeto, assim como de definir suas qualificações, e desde o princípio já tinha estabelecido o perfil das pessoas com as quais gostaria de engrossar suas fileiras, a fim de garantir o engajamento na animação popular, revelando de forma secundária, os aspectos cotidianos da prática escolar e do conteúdo das aulas. À medida que a experiência do MEB se desenvolveu, a preocupação pedagógica, incluindo os aspectos relacionados à formação, começou a aparecer de forma mais recorrente na programação radiofônica.

\section{COTIDIANO E A ALFABETIZAÇÃO NAS ESCOLAS RADIOFÔNICAS}

$\mathrm{O}$ ato de escrever uma carta revela, sobretudo, a necessidade de comunicação entre pessoas ausentes, o fim do silêncio entre as mesmas, ainda 
que possa existir uma distância geográfica entre elas (PETRUCCI, 2003). Desse modo, seu conteúdo possui diferentes motivações, relacionadas à necessidade de comunicar ao outro um sentimento, que pode ser de alegria, de gratidão, de inquietude ou de lamento. A carta também pode conter uma recomendação, um pedido de conselho ou de um favor, ou, simplesmente, contar uma boa nova. Ademais, as características de produção, circulação e a materialidade das cartas (CASTILLO GÓMEZ, 2005) nos dão indícios para conhecermos a relação que seus escreventes estabeleceram com a escrita e a leitura, além de como se apropriaram destas, por meio de práticas que possibilitaram seu uso como forma de comunicar suas experiências e expectativas.

Quais seriam, então, as experiências e expectativas que nos revelam as cartas por nós investigadas? Primeiramente, no que se refere às expectativas das monitoras e dos monitores em torno do trabalho de educação dos adultos, identificamos nos escritos uma correlação com a formação dada pelo MEB acerca de seu papel junto às escolas e à comunidade como animadores populares. Em muitas missivas era comum o uso de expressões e termos de conotação política e religiosa, comuns nos conteúdos de formação do MEB, nos treinamentos e nas aulas radiofônicas:

É com maior praser na vida que envio estas linhas quando sei pelo radio que toudos vivem satisfeitos com alunos e monitores deste sagrado movimento. Eu com isto me esclareço que fico com a alma cheia de alegria em ver os meus irmãos do campo receberem instrução por tão dignas professoras. Os alunos todos cheio entusiasmo não deixam de romperem as dificuldade a fim de receberem as instruções a noite chuvosa estrada coberta de lama mas com isto mesmo frequentão a escola. Já tem aluno que assina bem o nome que já adimira e assim espero que em pouco tempo teremos um brasil milhor com a promoção do homem do campo que vai desenvolvendo (Benedito, s.d, [grifo nosso]).

Termos bastante recorrentes, como animados e cheios de entusiasmo, irmãos, trevas do analfabetismo, luz da educação - que aparecem neste e em outros relatos - exprimem, a compreensão da tarefa que o monitor assumia no 
âmbito de sua comunidade, atribuindo o valor que o acesso à alfabetização possuía naquele contexto, como um lugar importante de atuação junto à sociedade e de participação política. Na carta, os monitores expressavam a crença na valorização da educação como meio para o desenvolvimento e a promoção do trabalhador rural, ambos vistos naquele contexto, como fatores necessários para um país desenvolvido:

\begin{abstract}
Uma parte dos alunos antigo desgostaram com os acontecimentos passados e deixaram a escola, de modo que substituir assim a lacuna deixada por alguns e assim estamos animados esperando que recomece as aulas. Certifico que estou bem entusiasmado acompanhando com muita atenção os capitulos da história de Tibiquera que nos esta sendo contado pelas professôras do Recife [...] Garantimos que vamos lutar com o máximo esforço possível afim de fazer progredir as escolas a nós confiadas para que em breve tenhamos muitos analfabetos alfabetizados. [...] Nós os monitores estamos prontos para ajudar aos alunos no que êles pressizarem [...] (Antonio Jorge, 20/07/64).
\end{abstract}

$\mathrm{O}$ relato do monitor, feito na primeira pessoa do plural, revela seu sentimento de pertencimento a um grupo, com o qual compartilhava a tarefa de alfabetizar e ajudar os alunos no que fosse preciso. O seu entusiasmo é, como nas demais cartas, expressão de um sentimento comum em relação à escola radiofônica e às aulas, e nomeado por um vocábulo aprendido ou ressignificado no próprio processo de alfabetização e de formação das monitoras e dos monitores.

Com relação a este aspecto, vale destacar a importância do rádio como veículo de troca de informações e experiências entre as escolas, tendo em vista as características do modelo de educação implementado pelo MEB. O rádio foi o meio pelo qual os conteúdos educativos foram transmitidos para os alunos, e também um veículo de formação e de troca de informações entre as diversas escolas radiofônicas: "quando sei pelo radio que toudos vivem satisfeitos". $\mathrm{Na}$ programação especial, que era veiculada aos finais de semana, havia o Programa do Monitor, destinado à formação política e pedagógica das monitoras e dos 
monitores. Havia também o Programa da Comunidade, voltado para a promoção da cultura popular, por meio de concursos de poesia e de cordel, além dos muitos pedidos musicais enviados nas cartas pelos ouvintes. De tal modo que, por meio de uma programação diversificada, foi possível a circulação dos conteúdos pedagógicos e políticos do Movimento, assim como da cultura popular, transformando as escolas radiofônicas em espaços de aprendizado, produção e circulação da cultura camponesa.

A crença no trabalho de alfabetização e no engajamento comunitário foi certamente o elemento catalisador da militância junto ao MEB e motivou os monitores a enfrentarem as maiores dificuldades para fazer com que a escola radiofônica não parasse de funcionar. Assim, lançavam mão de práticas que visavam contribuir para o desenvolvimento dos alunos e auxiliá-los na apropriação do conteúdo radioeducativo, amenizando suas dificuldades de aprendizado, se preciso tomando às lições, ensinando as letras, fazendo os exercícios no quadro. As monitoras que eram professoras aplicavam estratégias conhecidas com os alunos para dirimir suas dificuldades relacionadas às questões relativas à frequência nas aulas, à transmissão e à assimilação dos conteúdos. As cartas escritas pelos alunos, pelas monitoras e pelos monitores mencionam algumas das práticas que foram mobilizadas ao longo das aulas, com o objetivo de auxiliar os alunos em seu processo de aprendizagem:

Escrevo para dizer que estou muito satisfeito tanto com a senhora como com a monitora Silvya Cabral pois o ano passado quando entrei na escola não sabia de nada e hoje me acho bem adiantado [...] A monitora orienta nos de modo que entendemos com mais facilidade estamos muito satisfeitos com a monitora pois ela é a professora daqui todos gostam muito dela e é uma criatura de muito paciência (Amaro, 04/10/63).

[...] o radio transmite a aula de matemática eu dou a de linguagem sempre trocando entende, e no fim das aulas eu costumo tomar as lições de livros e taboadas, apenas as lições do eu só tomo quando é dada pelo rádio. Estará de acordo? (Marina, 02/10/63). 
[...] dei inicio a escola de Cacimbinha, [...], com uma frequência de 24 alunos, quase tudo analfabetos. Estou lutando com a maior dificuldade, dando o conhecimento das (23) lêtras do alfabeto no quadro (Clarindo, 03/07/64).

Os meus alunos são pocos mais são sempre animado, já lerem qualquer fraze escrevem todas frazes o nome dêles sem ver outro, estão moitos bem satisfeito com as professôras com migo por que eu explico o que êles não compreêndem direito (Josefa, 06/09/63).

[...] a hora de aula dada pelo rádio é pouca, mais meus alunos até o momento estão satisfeitos pois fico com os mesmos até 8 horas. No dia que vocês dão aula de Linguagem, eu dou de Matemática para que eles não reclame (Teresinha, 18/09/63).

[...] êles desanimaram um pouco por causa das aulas que foi mudado mais eu faço todo esforço e quando só tem uma aula eu dou a outra foi com isto que ficaram mais animados (Dione, 07/10/63).

Como relatado nas cartas, as monitoras realizavam o papel de professoras ao mediar à programação do $\mathrm{MEB}$, partindo de práticas comuns ao repertório docente, como o ato de "tomar" as lições e as contas, ensinar o alfabeto, realizar atividades de leitura e, até mesmo, adequando o conteúdo e o tempo das aulas, para melhor atender às necessidades de seus alunos. Desse modo, as monitoras e os monitores os auxiliavam diretamente nas suas lições e aprendizados, além de desempenharem a função de animadoras, que os entusiasmava não somente a frequentar a aulas, mas a progredir nos estudos. A importância que atribuíam ao seu trabalho na escola radiofônica como fator para o desenvolvimento da comunidade e aprendizado dos alunos contribuía para que lançassem mão de tais práticas, na busca por superar as dificuldades relacionadas ao processo de aprendizagem nas escolas.

Por outro lado, se em muitos momentos a atuação das monitoras e dos monitores se estabelecia por meio da adesão, também vemos nas cartas os movimentos de recusa como, por exemplo, quando remetem suas críticas em 
relação à qualidade das aulas, cobram das professoras locutoras mais atividades e melhor aproveitamento do tempo. Além das críticas, também remetiam nas cartas suas dúvidas sobre o conteúdo das aulas e a organização das escolas. Nesse aspecto, os monitores e, em muitas ocasiões, também os alunos, tiveram um papel ativo na elaboração do currículo veiculado pelo rádio.

Sobre as dificuldades cotidianas relacionadas ao conteúdo da programação radiofônica a monitora escreve:

Tenho ouvido que só pode funcionar com 15 alunos, porem acho que se os 10 alunos tem vontade, e muita bôa vontade de aprender, não pudera a Escola funcionar? Pois só continuo como monitora porque gosto muito dos meus alunos e vejo que eles tem muita bôa vontade para aprender, portanto espero que seja compreendida. [...] Eles pedem para a professora de Portugueis, passar a lição de leitura touda pois só 4 frazes é muito pouco. Eu também acho pois eles tem muita pratica na leitura da cartilha, o que eles pressizam é de pratica na escrita [...]. O tempo para escrever é pouquissimo. Êles dizem que o tempo da aula é pouco e vocês ficam só com música e não esplicam as coiza. Eu acho que estes poucos minutos devem serem bem aproveitados, para recompença os esforços e sacrificios que eles fazem para virem as aulas [...]. Seria milhor que lecem a lição touda e esplicasse tudo direito, como bem acento e pontuação, que os alunos estão interessados em aprender. [...] Vejo que os alunos não ficam satisfeitos em ficarem lendo só aquelas 4 frases repetindo 10 vezes até feixar a cartilha e fazerem caretas um para os outros, ouvindo aquela muziquinha ensôssa! [...] Aquele tempo toudo ela divia dar para eles escreverem, pois quando ela manda escrever que eles pegam no caderno que poem no juelho (pois não tem carteira) antes de fazerem a premeira palavra ela diz (já terminaram?) Sim o Aladim não nos serve para nada, está vazando querozene, aquilo é um abacaxi e afinal é o que tenho topado como monitora, é só abacaxi, já estou de saco cheio, mas um dia êle vaza (Terezinha, 04/05/64).

Terezinha termina sua carta em tom de desabafo e a intenção de deixar a função. É fato que muitas monitoras e monitores desistiam diante das dificuldades de ordem material ou técnica. Manifestavam seus sentimentos de frustração, tendo em conta as condições materiais adversas de que dispunham para realizar seu trabalho, para tornar possível e bem sucedido o aprendizado de 
seus alunos. Os problemas de ordem material, a baixa frequência, o desinteresse dos alunos e questões de ordem pessoal, envolvendo problemas de saúde e familiares, foram motivos que levaram ao fechamento de algumas escolas:

Venho por meio desta dizer lhes que por motivo de força maior não é possível continuar com o meu cargo de monitora. [...] A dias estive doente como voces devem saber, [...], e eu não posso continuar pois já ensino a tarde e tenho bastante luta em casa e sou sozinha [...]. E mesmo assim, os alunos não estão muito enteressados o enteresse aqui só é o meu e por isto acho que não é interessante pra mim ficar com esse cargo com tanto sacrificio pois na hora certa tenho que deixar tudo que possa que não possa e ir para a sala, muitas vezes vem só fazer barulho e nada prestam atenção depois acham que eu devo ficar horas e horas ensinando conta etc. E nem se quer querem cooperar com a compra das pilhas para o rádio que já o outro material eu não falo que deixo por minha conta como seja: gaz, giz e dou também a sala a onde eles estudam, para ver se assim tomam gosto e a escola pudesse continuar mais no entanto, não foi possível. Quando se fala para um diz é quando eu enricar eu dou, outro diz é quando eu puder, e assim vai se passando e nada dão. E a vida e mangarem dos alunos mais atrazados, e eles se desgostam não querem vir mais, e assim são estas confusões todas por isso devo desistir (Albertina, 09/07/64).

Outra questão que levava à desistência das monitoras e dos monitores era as próprias demandas relacionadas aos conteúdos das aulas, que muitos não conseguiam resolver devido à sua precária formação escolar. Supunha-se, inicialmente, que a atuação do monitor se concentraria mais nas tarefas de organização e gestão das escolas radiofônicas do que na parte didática (FÁVERO, 2006). Porém, com os frequentes problemas com as emissões radiofônicas, e à medida que o trabalho do MEB se desenvolveu, os treinamentos, ocasiões de estudo e as aulas radiofônicas, transmitidas em horários alternativos, passaram a ser utilizados como recursos para completar a formação das monitoras e dos monitores, demandada com frequência nas cartas, em face das dificuldades em trabalhar os conteúdos com os alunos.

Pela ausência de pontuação, erros de ortografia e separação de sílabas que a monitora apresenta em sua carta, se notam as dificuldades que tinha com 
o manejo da língua e da escrita, o que torna mais compreensível sua dificuldade em ajudar os alunos durante as aulas:

Dona Edina eu vou dexa mais e pro isto parque ais aulas que a senhora e outra estão dando eu não quase não compriendo di nada que eu não [?] Arimitica não ço passi primeira serí eu estou muito pençativa parque não pasco comsiguir o pai tumar lição com a profescoura Maria dos Prazer ela falou quí eu não tive estudo para este trabâlho não ço para ela qui estudou 5 anos eu estude 2 ela é prodescoura municipal conhese tudo então respasti ci esta serto a sim eu entrego ais coiza tudos o radio esta bom pode ficar para outra ate eu mesmo pasço entregar uma monitora que o dela não presta (GRIMAURA, o8/o8/64).

Mais uma questão relatada nas cartas era a dificuldade em conversar ou promover ocasiões de debates com os alunos após as aulas, sobre assuntos que apesar de fazerem parte do conteúdo pedagógico do MEB, e de serem temas que procuravam dialogar com a realidade dos trabalhadores rurais, não eram fáceis de serem debatidos pelas monitoras e monitores. Alguns tratam da dificuldade em promover o debate sobre alguns temas com os alunos, principalmente, aqueles relacionados ao conteúdo das aulas de Conhecimentos Gerais cujo currículo era mais abrangente e variado, com temas relacionados à participação política, organização do Estado, acesso à terra e condições de trabalho:

É uma luta quase inútil a nossa, pois o pouvo, não querem entender, as coisa na realidade. Quanto as aulas de conhecimento gerais êles não ligam muita atenção; o papel do monitor é quase inútil neste ponto pois as vezes nossa capassidade é pouca, nosso saber também, para conversar, assuntos tão [ilegível] do comum para eles como seja: sindicato, reforma agrária, etc (Terezinha, 04/10/63).

Para algumas monitoras e monitores o fracasso de suas escolas radiofônicas estava relacionado à falta de interesse dos alunos em frequentar as aulas. Nesse aspecto revelavam a ideia da existência de inércia, da ignorância e do desinteresse por parte dos alunos, o que impedia às pessoas de buscarem o 
conhecimento sobre a realidade. Por um lado, esses relatos reforçavam o estereótipo em torno das pessoas analfabetas, como carentes de algo, deficientes ou, até mesmo, doentes como já defendido em outros contextos (ROCHA, 1995; FREITAS; BICCAS, 2009). Por outro lado, os relatos também sublinhavam que a falta de vontade dos alunos em frequentar a escola, em muitos casos, estava relacionada à sua condição de trabalhador rural, ao cansaço ou a dificuldades maiores, relativas aos ciclos do trabalho rural, que os impedia de frequentar diariamente a escola por alguns períodos do ano. Assim, por meio desses escritos revelavam a apreensão do analfabetismo para além do sujeito analfabeto, compreendendo-a como um fenômeno mais amplo, fruto das condições de existência do povo camponês.

Sabe-se também que a valorização da necessidade do escrito é característica das sociedades em que a oralidade já não é mais a única forma de comunicação, ademais de estar relegada a um segundo plano (VINÃO FRAGO, 1992). Essa valorização do escrito sobre o oral, a partir do qual se sustenta o modelo ocidental de escolarização moderna, hierarquizou as formas de comunicação e determinou quais linguagens estariam mais aptas a estabelecer uma experiência mais transformadora com a realidade. Desse modo, a valorização do escrito numa sociedade de analfabetos conferiu ao trabalho das monitoras e dos monitores, uma relevância social, que foi reforçada pelo MEB tanto nos treinamentos como por meio da programação radiofônica.

\section{CONCLUSÃO}

As múltiplas experiências que configuraram as escolas radiofônicas de Pernambuco deixam claro que, por um lado, o MEB elaborou seu discurso sobre a vida dos camponeses e delineou os parâmetros pelos quais ela deveria ser transformada, tendo em vista sua concepção em torno da alfabetização dos adultos e da educação de base, a partir do diálogo com a comunidade e de sua mobilização. Por outro lado, as cartas de monitoras e monitores revelam as 
estratégias cotidianas para a condução da escola radiofônica, diante das condições existentes, que ultrapassaram o que era prescrito, e foram decisivas para que a experiência do MEB fosse significativa naquele contexto.

As cartas expressam uma consciência em torno da importância do acesso à alfabetização, por parte das comunidades atendidas pelas escolas, tendo em vista as estratégias mobilizadas pelas monitoras e pelos monitores, para que os alunos pudessem ser alfabetizados. Também relatam seu engajamento para que as escolas radiofônicas pudessem funcionar, diante das dificuldades relacionadas às precárias condições de infraestrutura que dispunham, e da carência de recursos econômicos. Tais práticas, como por exemplo, a organização de festas e de rifas para arrecadação de dinheiro, necessário para a compra de materiais didáticos, das pilhas para o rádio e do querosene para o lampião (ALVES, 2016), revelam o engajamento desses educadores e das comunidades, diante da carência de escolas públicas nos meios rurais, e da demanda pelo acesso à alfabetização. Tal demanda está historicamente presente na sociedade brasileira, que nos anos de 1960, contava com 39,6\% de analfabetos, segundo Censo do IBGE (FREITAS; BICCAS, 2009).

Essa consciência para a ação não pode ser valorada pelo seu potencial crítico acerca da realidade, como estava previsto na proposta pedagógica do MEB, mas era fruto da experiência direta do camponês e das condições que dificultavam sua vida: pobreza, carência de recursos e de instrumentos de trabalho, falta de água e acesso a terra e à educação, entre outros. Como sugere Edward Palmer Thompson ao falar da formação da consciência entre os trabalhadores ingleses, eles "aprenderam a contemplar suas próprias vidas" (THOMPSON, 2002, p. 93). Essa consciência, que nasce da experiência, não estava restrita à experiência escolar em torno do MEB, mas circulava nas cartas, nos poemas, na literatura de cordel, nas cantigas populares, assim como, por meio de práticas disseminadas naqueles espaços, como a leitura em voz alta dos textos de cordel, nas festas, praças e feiras (GALVÃO, 2001, 2011).

Os escritos epistolares contêm indícios da vida cotidiana nas escolas 
radiofônicas e das pessoas que delas fizeram parte. Foi o trabalho das monitoras e dos monitores, na condição de membros da mesma comunidade, assim como o engajamento destas comunidades nas atividades das escolas, que conferiu dinâmicas próprias para a experiência proposta pelo MEB. Se, por um lado, essas experiências foram capazes de criar ou reforçar as representações relativas ao lugar dos analfabetos na sociedade brasileira e ao MEB em sua dimensão política de atuação, por outro, nos revelam os momentos em que a realidade material e a cultura dos camponeses deram significados próprios àquela experiência educacional.

\section{REFERÊNCIAS}

ALENCAR, Albertina. Carta às supervisoras, 09/07/1964, caixa 2(2).

ALVES, Dione Maria. Carta às supervisoras do MEB, 07/10/1963, Sítio Palmeira, caixa 2(1).

ALVES, Kelly Ludkiewicz. Entre as cartas e o rádio: a alfabetização nas escolas radiofônicas do Movimento de Educação de Base em Pernambuco (19611966). 2016. 160 f. Tese (Doutorado em Educação) - Programa de PósGraduação em História, Política, Sociedade, Pontifícia Universidade Católica de São Paulo/PUC-SP, São Paulo, 2016.

ANDRADE, Grimaura Gomes de. Carta à D. Edna, 08/08/1964, Sitio Serra/Panelas, caixa 2(2).

BEISIEGEL, Celso de Rui. Estado \& educação popular. Brasília: Liber Livro, 2004.

CASTILLO GÓMEZ, Antonio. De la mano al archivo. A guisa de prólogo. In: CASTILLO GÓMEZ, Antonio (ed.), La conquista del alfabeto. Escritura y classes populares. Gijón: Trea, 2002.

CASTILLO GÓMEZ, Antonio. Historia de la cultura escrita: ideas para el debate. Revista Brasileira de História da Educação, 1(5), p. 93-124, jan. 2003.

CASTILLO GÓMEZ, Antonio. 'El mejor retrato de cada uno'. La materialidad de la escritura epistolar en la sociedad hispana de los siglos XVI y XVII. Hispania, 
$\mathrm{LXV} / 3,221$, p. 847-876, 2005.

CASTILLO GÓMEZ, Antonio; SIERRA BLAS, Verónica. Cinco siglos de cartas. História y prácticas epistolares en las épocas moderna y contemporânea, Huelva: Universidad de Huelva, 2014.

CHARTIER, Roger. História da educação e história da cultura escrita. In: CURY, Cláudia Engler; VIEIRA, Carlos Eduardo; SIMÕES, Regina Helena Silva (org.). História da educação: global, nacional e regional. Vitória: Edufes, 2019.

COSTA, Maria Aída Bezerra; BRANDÃO, Carlos Rodrigues. A questão política da educação popular. 5. ed. São Paulo: Brasiliense, 1985.

FÁVERO, Osmar. Uma pedagogia da participação popular: análise da prática educativa do MEB - Movimento de Educação de Base (1961/1966). Campinas: Autores Associados, 2006.

FERRARI, Alceu. Igreja e desenvolvimento: o movimento de Natal. Natal: Fundação José Augusto, 1968.

FREITAS, Marcos Cezar de; BICCAS, Maurilane de Souza. História social da educação no Brasil (1926-1996). São Paulo: Cortez Editora, 2009.

GALVÃO, Ana Maria de Oliveira. Cordel: leitores e ouvintes. Belo Horizonte: Autêntica Editora, 2001.

GALVÃO, Ana Maria de Oliveira (org.). História da cultura escrita: séculos XIX e XX. Belo Horizonte: Autêntica Editora, 2007.

KADT, Emanuel de. Católicos radicais no Brasil. Brasília: Unesco, MEC, 2007.

MATOS, Clarindo Vieira. Carta às supervisoras, 03/07/1964, Cacimbinha, caixa 2(2).

MEB/Centro Radiofônico de Educação Rural. Relatório de treinamento de monitores. Nazaré da Mata. 1961. 26 p.

MEB. Documentos Legais. Apostila 1, série A. s/l. s/d. 35 p.

MEB. O Monitor. Apostila 4. s/d. s/l. 19 p.

MEB/Sistema Radioeducativo de Olinda e Recife. Programa do Monitor. 1963. $8 \mathrm{p}$.

MEB. Escolas Radiofônicas do MEB notas sobre seus objetivos, sua programação e sobre o desenvolvimento dos alunos. [1964]. 21 p. 
NETO, Terezinha. Carta às supervisoras, 04/10/1963, s.l, caixa 2(1).

NETO, Terezinha. Carta à Mundica, 04/05/1964, Várzea do Mulungu, caixa 2(3).

OLIVEIRA, Benedito Medeiros de. Carta às professoras do MEB, s.d, s.l, caixa 2(3).

PAIVA, Vanilda. Educação popular e educação de adultos. São Paulo: Edições Loyola, 1983.

PEREIRA, Amaro José. Carta à supervisora, 04/10/1963, Junco, caixa 2(1).

PETRUCCI, Antonio. La ciencia de la escritura. Primera lección de paleografia. Buenos Aires: Fondo de Cultura Econômica, 2003.

SOARES, Leôncio; GALVÃO, Ana Maria de Oliveira. Uma história da alfabetização de adultos no Brasil. In: STEPHANOU, Maria; BASTOS, Maria Helena Camara (org.). Histórias e memórias da educação no Brasil. V. III - Séc. XX. Petrópolis, RJ: Editora Vozes, 2011.

ROCHA, Heloísa Helena Pimenta. Imagens do analfabetismo: a educação na perspectiva do olhar médico no Brasil dos anos 20. Trajetos, v. 2, n. 4(5), p. 1730, ago. 1995 .

RODRIGUES, Maria do Carmo. Carta às supervisoras, 06/08/1964, Cazuzinha, caixa 2(2).

SANTOS, Maria José dos. Carta às supervisoras e professoras, 02/10/1963, Carpina, caixa 2(1).

SANTOS, Raimunda Alves dos. Carta à supervisora Maria Helena, 23/06/1964, s.l, caixa 2(2).

SEBASTIANA, Eliza. Carta à supervisora, s/d, s/l, caixa 4(1).

SILVA, Teresinha Belermino da. Carta à supervisora, 18/09/1963, Upatininga, caixa 2(2).

SILVA, Antonio Jorge da. Carta à professora Marliete, 20/07/1964, Condado, caixa 2(2).

SOUZA, Claudia Moraes de. Pelas ondas do rádio: cultura popular, camponeses e o Movimento de Educação de Base. 2006. 367 f. Tese (Doutorado em História) - Programa de Pós-Graduação em História Social, Faculdade de Filosofia, Letras e Ciências Humanas, Universidade de São Paulo/USP, São 
Paulo, 2006.

SOUZA, José Pereira de. Carta à Dinalva Sá, 14/05/1964, Penha da Serra, caixa 2(3).

TEIXEIRA, Wagner da Silva. Educação em tempos de luta: história dos movimentos de educação e cultura popular (1958-1964). 2008. 229 f. Tese (Doutorado em História) - Programa de Pós-Graduação em História da Universidade Federal Fluminense/UFF, Niterói, 2008.

THOMPSON, Edward Palmer. La consciencia de clase: de la formación de la clase obrera en Inglaterra. In: THOMPSON, Dorothy (ed.). E. P. Thompson: obra essencial. Barcelona: Critica, 2002.

VEYNE, Paul. Como se escreve a história e Foulcault revoluciona a história. Brasília: Editora Universidade de Brasília, 2014.

VIÑAO FRAGO, Antonio. Alfabetización y alfabetizaciones. In: ESCOLANO BENITO, Agustín (org.). Leer y escribir en España: doscientos años de alfabetización. Madrid; Salamanca: Fundación Germán Sánchez Ruipérez, 1992. WANDERLEY, Luís Eduardo. Educar para transformar. Petrópolis: Vozes, 1984 .

WILLIAMS, Raymond. Cultura. São Paulo: Paz e Terra, 1992.

KELLY LUDKIEWICZ ALVES é professora do Departamento de Educação I, área História da Educação Brasileira, da Faculdade de Educação (FACED) da Universidade Federal da Bahia (UFBA). Coordenadora do Núcleo de Pesquisa e Memória de História da Educação da FACED-UFBA e do Cineclube Vesúvio. Membro do Grupo de Pesquisa Educação, Comunicação e Tecnologias (GEC/FACED). Pesquisa na área de História da Educação Brasileira, com ênfase nos seguintes temas: escola e cultura; educação popular; alfabetização de adultos; educação radiofônica; educação e movimentos sociais, história da cultura escrita e escrita epistolar.

E-mail: kelly.alves@ufba.br

(b) http://orcid.org/0000-0002-5487-2758 
Revista História da Educação (Online), 2020, v. 24: e98643 DOI: http://dx.doi.org/10.1590/2236-3459/98643
e-ISSN: 2236-3459

http://seer.ufrgs.br/asphe

Recebido em: 29 de novembro de 2019

Aprovado em: 18 de março de 2020

(c) (

Associação Sul-Rio-Grandense de Pesquisadores em História da Educação - Asphe Artigo de acesso aberto distribuído nos termos de licença Creative Commons. 